\title{
Gingival fluid cytokine expression and subgingival bacterial counts during pregnancy and postpartum: a case series
}

\author{
Regina Alessandri Bieri • Laurence Adriaens • \\ Stefan Spörri • Niklaus P. Lang • G. Rutger Persson
}

Received: 21 March 2011 / Accepted: 4 January 2012 / Published online: 17 January 2012

(C) Springer-Verlag 2012

\begin{abstract}
Objectives The aim of this study was to assess gingival fluid (GCF) cytokine messenger RNA (mRNA) levels, subgingival bacteria, and clinical periodontal conditions during a normal pregnancy to postpartum.

Materials and methods Subgingival bacterial samples were analyzed with the checkerboard DNA-DNA hybridization method. GCF samples were assessed with real-time PCR including five proinflammatory cytokines and secretory leukocyte protease inhibitor.

Results Nineteen pregnant women with a mean age of 32 years (S.D. \pm 4 years, range $26-42$ ) participated in the study. Full-mouth bleeding scores (BOP) decreased from an average of $41.2 \%$ (S.D. $\pm 18.6 \%$ ) at the 12 th week of pregnancy to $26.6 \%$ (S.D. $\pm 14.4 \%$ ) at the $4-6$ weeks postpartum $(p<0.001)$. Between week 12 and $4-6$ weeks postpartum, the mean probing pocket depth changed from $2.4 \mathrm{~mm}$ (S.D. \pm 0.4$)$ to $2.3 \mathrm{~mm}$ (S.D. \pm 0.3$)(p=0.34)$.
\end{abstract}

R. A. Bieri · L. Adriaens · G. R. Persson $(\bowtie)$

Department of Periodontology, University of Bern,

Freiburgstrasse 7,

CH-3010 Bern, Switzerland

e-mail: rutger.persson@zmk.unibe.ch

\section{S. Spörri}

Department of Obstetrics and Gynecology,

State Hospital of Fribourg,

Fribourg, Switzerland

\section{N. P. Lang}

Faculty of Dentistry, Prince Philip Dental Hospital,

The University of Hong Kong,

Hong Kong, SAR, People's Republic of China

\section{G. R. Persson}

Department of Periodontics and Department of Oral Medicine, University of Washington,

Seattle WA, USA
Higher counts of Eubacterium saburreum, Parvimonas micra, Selenomonas noxia, and Staphylococcus aureus were found at week 12 of pregnancy than at the 4-6 weeks postpartum examinations $(p<0.001)$. During and after pregnancy, statistically significant correlations between BOP scores and bacterial counts were observed. BOP scores and GCF levels of selected cytokines were not related to each other and no differences in GCF levels of the cytokines were observed between samples from the 12th week of pregnancy to 4-6 weeks postpartum. Decreasing postpartum counts of Porphyromonas endodontalis and Pseudomonas aeruginosa were associated with decreasing levels of Il8 and Il- $1 \beta$.

Conclusions BOP decreased after pregnancy without any active periodontal therapy. Associations between bacterial counts and cytokine levels varied greatly in pregnant women with gingivitis and a normal pregnancy outcome. Postpartum associations between GCF cytokines and bacterial counts were more consistent.

Clinical relevance Combined assessments of gingival fluid cytokines and subgingival bacteria may provide important information on host response.

Keywords Pregnancy - Bacteria $\cdot$ Cytokine - Gingival inflammation · Gingival crevicular fluid

\section{Introduction}

During pregnancy, gingival inflammation is common. Pregnancy gingivitis usually resolves spontaneously within a few weeks after delivery [1-3]. Data suggest that temporary clinical periodontal changes during pregnancy do not result in an increased risk for future periodontitis [4]. During the second trimester of pregnancy, a shift of the subgingival 
levels of Prevotella intermedia and Porphyromonas gingivalis has been observed [2, 5,6]. Other authors have not found any differences in the composition of the oral biofilm between pregnant and nonpregnant women [4, 7]. Why within a few weeks after delivery, increased gingival inflammation during pregnancy is quickly resolved, remains unclear. In a previous publication including the same subjects as in the present work, we identified that bacterial counts of bacteria associated with periodontitis did not change during pregnancy or to a time point at 4-6 weeks postpartum [8].

Recent data suggest that cytokine levels in saliva may be linked to the periodontal status [9]. Other studies have not been able to demonstrate that salivary levels of granulocyte-macrophage colony-stimulating factor (GM-CSF), interleukin- $1 \beta$ (IL-1ß), interleukin-2 (IL-2), interleukin-4 (IL-4), interleukin5 (IL-5), interleukin-6 (IL-6), interleukin-8 (IL-8), interleukin10 (IL-10), interferon- $\gamma($ IFN- $\gamma$ ), and tumor necrosis factor- $\alpha$ (TNF- $\alpha$ ) can discriminate between periodontal health and disease [10].

Studies of cytokine levels in gingival crevicular fluid (GCF) have suggested that TNF- $\alpha$ levels are lower at healthy sites in periodontally healthy subjects than in subjects with advanced periodontitis, who have high levels of TNF- $\alpha$ in GCF both at sites with or without evidence of disease [11]. The influence of sex hormones on proinflammatory cytokines in GCF of healthy premenopausal, nonpregnant women has recently been studied. No associations between clinical periodontal parameters, hormonal changes, and differences in GCF cytokine levels were found [12]. In a study with pregnant women, exacerbated gingival inflammation during pregnancy could not be associated with increased salivary progesterone or estradiol levels or increased levels of proinflammatory cytokines [13].

Secretory leukocyte protease inhibitor (SLPI) is present in human fluids and also in gingival tissues [14]. SLPI is a common antimicrobial protein of the upper airways [15] inhibiting LPS and nuclear factor- $\mathrm{KB}(\mathrm{NF}-\mathrm{kB})$ activation [16]. SLPI exhibiting strong antibacterial activities has been identified in GCF [17]. Furthermore, SLPI causes an upregulation of the production of anti-inflammatory cytokines [18]. In vitro studies have, however, also recently demonstrated that argininespecific gingipains of $P$. gingivalis inhibit the protective effects of SLPI [14]. Currently, it is unknown if GCF levels of SLPI change during pregnancy, or if the presence or absence of oral bacteria influences the GCF levels of SLPI in pregnancy.

Up to date, we have only limited information about the relationship between bacteria in periodontal pockets/sulci and the presence or absence of proinflammatory cytokines in pregnant women. Therefore, the purposes of the present study were to assess:

1. Microbiological changes between week 12 of pregnancy to 4-6 weeks postpartum and in relation to changes in gingival inflammation (percent sites with bleeding on probing (BOP)) between week 12 of pregnancy and 4 6 weeks postpartum

2. The association between levels of mRNA of proinflammatory cytokines in gingival fluid and the severity of gingival inflammation (percent sites with BOP) at week 12 of pregnancy and 4-6 weeks postpartum

3. Differences in GCF cytokine levels of mRNA (IL- $1 \alpha$, IL-1 $\beta$, IL- 8, TNF- $\alpha$, and SLPI) at the 12th week of pregnancy and 4-6 weeks postpartum

4. The association between changes in bacterial and cytokine levels between week 12 of pregnancy and 4-6 weeks postpartum

\section{Materials and methods}

The Institutional Review Board of the Cantons of Jura, Fribourg, and Neuchâtel, Switzerland approved the present study. All the participating subjects signed informed consent. The study was a prospective consecutive case series over the period of pregnancy (from week 12 through 4-6 weeks postpartum) without study-defined medical or dental interventions.

\section{Subject population}

Pregnant women, 18 years of age or older, attending the Department of Obstetrics and Gynecology at the State Hospital of Fribourg, Switzerland and with singleton pregnancy were included. Women with known congenital uterine malformations, congenital vaginal malformations, fetal malformation, multifetal gestation, and with chronic diseases (e.g., diabetes, hypertension, epilepsy, cardiac disease, lung disease, renal disease, and positive test for human immunodeficiency virus (HIV)) were excluded. All the participating women were monitored by standard of care principles at the Department of Obstetrics and Gynecology. The subjects were recruited between April and October 2006. None of the women had received periodontal therapy before and during pregnancy.

\section{GCF sampling and processing}

GCF was collected with sterile endodontic paper points (absorbent paper points, Dentsply/Maillefer, Ballaigues, Switzerland), and parallel to this procedure, subgingival bacterial samples were also collected using sterile endodontic paper points. GCF and subgingival bacterial samples were harbored from the mesiobuccal aspects of all first molars, and each paper point remained in situ for $15 \mathrm{~s}$. The first molars were chosen while these teeth are 
commonly present in young adults and evidence of inflammation at these teeth are common. In addition, the first molars are simple to isolate and easy to collect samples from. The samples were placed in separate Eppendorf tubes (1.5 ml natural flat cap microcentrifuge tubes, Starlab, Ahrensburg, Germany) for the assessment of cytokines and bacteria. All the samples were immediately transported on dry ice to the Oral Microbiology Laboratory of the University of Bern, Switzerland for processing.

\section{Clinical examination}

A full-mouth periodontal examination with the assessments of BOP and probing pocket depth (PPD) was performed at the 12th week of pregnancy and at a visit 4-6 weeks after delivery. BOP, PPD, and gingival recession were measured at six sites per tooth using the Florida probe ${ }^{\circledR}$ system (Florida Probe Corporation, Gainesville, FL, USA) with a standardized pressure of $0.15 \mathrm{~N}$. The same examiner (L. A.) performed the periodontal measurements. Gingivitis was defined as having $>20 \%$ of sites with BOP if periodontitis was not found. Periodontitis was defined as having periodontal sites with probing pocket depths $>4 \mathrm{~mm}$ and with radiographic evidence of alveolar bone loss as defined from post pregnancy intraoral radiographs.

\section{Analysis of subgingival bacterial samples}

The bacterial samples were stored at $-20^{\circ} \mathrm{C}$ and processed after a standard storage period of 3 months. To each sample, $0.15 \mathrm{ml}$ TE $(10 \mathrm{mM}$ Tris-HCL, $1 \mathrm{mM}$ EDTA, $\mathrm{pH}$ 7.6) and $0.5 \mathrm{ml} \mathrm{NaOH}$ were added. All the bacterial samples were analyzed with the checkerboard DNA-DNA hybridization technique. The 74 species assessed are presented in Table 1. The checkerboard DNA-DNA hybridization was performed as described elsewhere [19, 20]. Briefly, bacterial DNA was extracted using the method of Smith et al. [21], concentrated on nylon membranes (Roche Diagnostics GmbH, Mannheim, Germany), and fixed by cross-linking using ultraviolet light (Stratalinker 1800, Stratagene, La Jolla, CA, USA). The membranes with fixed DNA were placed in a Miniblotter 45 (Immunitics, Cambridge, MA, USA). Signals were detected by fluorescence using the Storm Fluor-Imager (Storm 840, Amersham Biosciences, Piscataway, NJ, USA) with a setup of $200 \mu \mathrm{m}$ and $600 \mathrm{~V}$. The digitized information was analyzed by a software program (ImageQuant, Amersham Pharmacia, Piscataway NJ, USA), allowing comparison of the density of the 19 sample lanes against the 2 standard lanes $\left(10^{5}\right.$ or $10^{6}$ cells $)$. Signals were converted to absolute counts by comparisons with these standards [19]. Subject-based mean values for bacterial counts of these species were calculated and used in the assessments.

\section{GCF analysis of cytokines}

\section{RNA extraction}

The GCF samples were frozen at $-79^{\circ} \mathrm{C}$. After thawing, the lysis buffer (RNAqueous ${ }^{\circledR}$-Micro kit, Ambion, Austin, TX, USA) was added to the Eppendorf tube for $10 \mathrm{~min}$. EtOH $100 \%$ was added, and the mixture was loaded on the Micro Filter Cartridge assembly (RNAqueous ${ }^{\circledR}$-Micro kit, Ambion, Austin, TX, USA). Further processing was performed according to manufacturer's instructions. The eluted RNA was treated with DNAse 1 (RNAqueous ${ }^{\circledR}$-Micro kit, Ambion, Austin, TX, USA).

\section{Reverse transcription and quantitative real-time polymerase} chain reaction

The total RNA used for quantitative real-time polymerase chain reaction (QRT-PCR) was reversely transcribed using random primers and MultiScribe ${ }^{\mathrm{TM}}$ reverse transcriptase according to manufacturer's instructions (high-capacity cDNA reverse transcription kit, Applied Biosystems, Foster City, CA, USA). Transcribed reactions were analyzed in real-time on an ABI 7500 (Applied Bio Systems, Foster City, CA, USA) using TaqMan ${ }^{\circledR}$ Universal PCR Master Mix (Applied Biosystems, Foster City, CA, USA). Primers and probes for detection of cytokines were all purchased from Applied Biosystems. Thermal cycling parameters were $50^{\circ} \mathrm{C}$ for $2 \mathrm{~min}, 95^{\circ} \mathrm{C}$ for $10 \mathrm{~min}$, followed by 40 cycles of $95^{\circ} \mathrm{C}$ for $30 \mathrm{~s}$ and $60^{\circ} \mathrm{C}$ for $1 \mathrm{~min}$. Reactions were performed in triplicates and threshold cycle numbers were averaged. The threshold data generated were normalized to GAPDH and UBB, calculating $\Delta$ ct. These housekeeping genes were chosen after analyzing 10 different endogenous controls with 12 GCF samples. The amount of cDNA was standardized for all reactions. The samples were collected from 12 different randomly selected nonpregnant individuals and therefore not part of the study (data not shown).

\section{Statistical methods}

Statistical analysis was performed using Wilcoxon signed rank test for within subject changes over time. MannWhitney $U$ tests were also used to assess changes over time. Correlation coefficients between parameters were assessed by Pearson correlation coefficient. Analysis by linear (stepwise) regression was performed to identify explanatory models to GCF cytokine changes during pregnancy. 
Table 1 Bacteria included in the checkerboard DNA-DNA hybridization assays

\begin{tabular}{|c|c|c|c|}
\hline Bacteria & Collection & Bacteria & Collection \\
\hline Aggregatibacter actinomycetemcomitans (a) & ATCC29523 & Actinomyces neuii & GUH550898 \\
\hline Aggregatibacter actinomycetemcomitans $(Y)$ & ATCC43718 & Aerococcus christensenii & GUH070938 \\
\hline Actinomyces israelii & ATCC 1201 & Anaerococcus vaginalis & GUH290486 \\
\hline Actinomyces naeslundii & ATCC121045 & Atopobium parvulum & GUH160323 \\
\hline Actinomyces odontolyticus & ATCC17929 & Atopobium vaginae & GUH010535 \\
\hline Capnocytophaga gingivalis & ATCC33612 & Bacteroides ureolyticus & GUH080189 \\
\hline Capnocytophaga ochracea & ATCC33596 & Bifidobacterium biavatii & GUH071026 \\
\hline Capnocytophaga sputigena & ATCC33612 & Bifidobacterium bifidum & GUH070962 \\
\hline Campylobacter gracilis & ATCC33236 & Bifidobacterium breve & GUH080484 \\
\hline Campylobacter rectus & ATCC33238 & Bifidobacterium longum & GUH180689 \\
\hline Campylobacter showae & ATCC451146 & Corynebacterium nigricans & GUH450453 \\
\hline Eikenella corrodens & ATCC238345 & Corynebacterium aurimucosum & GUH071035 \\
\hline Eubacterium saburreum & ASTCC 33271 & Dialister $s p$ & GUH071035 \\
\hline Fusobacterium nucl. naviforme & ASTCC49256 & Enterococcus faecalis & GUH170812 \\
\hline Fusobacterium.nucl.nucleatum & ATCC25586 & Enterococcus faecalis & ATCC29212 \\
\hline Fusobacterium.nucl. polymorphum & ATCC10953 & Echerichia coli & GUH070903 \\
\hline Fusobacterium periodonticum & ATCC33993 & Gardnerella vaginalis & GUH080585 \\
\hline Lactobacillus acidophilus & ATCC11975 & Haemophilus influenzae & ATCC49247 \\
\hline Leptothrichia buccalis & ATCC14201 & Helicobacter pylori & ATCC43504 \\
\hline Neisseria mисова & ATCC 33270 & Lactobacillus crispatus & GUH160342 \\
\hline Parvimonas micra & ATCC19696 & Lactobacillus gasseri & GUH170856 \\
\hline Prevotella intermedia & ATCC25611 & Lactobacillus iners & GUH160334 \\
\hline Prevotella melaninogenica & ATCC25845 & Lactobacillus jensenii & GUH160339 \\
\hline Prevotella nigrescens & ATCC33563 & Lactobacillus vaginalis & GUH0780928 \\
\hline Porphyromonas gingivalis & ATCC33277 & Mobiluncus curtisii & GUH070927 \\
\hline Propionybacterium acnes & ATCC $11827 / 28$ & Mobiluncus mulieris & GUH070926 \\
\hline Selenomonas noxia & ATCC43541 & Peptoniphilus sp. & GUH550970 \\
\hline Streptorcoccus anginosus & ATCC33397 & Peptostreptococcus anaerobius & GUH160362 \\
\hline Streptococcus constellatus & ATCC27823 & Porphyromonas endodontalis & ATCC35406 \\
\hline Streptococcus gordonii & ATCC10558 & Prevotella bivia & GUH450429 \\
\hline Streptococcus intermedius & ATCC27335 & Prevotella disiens & GUH190184 \\
\hline Streptococcus mitis & ATCC49456 & Proteus mirabilis & GUH070918 \\
\hline Streptococcus mutans & ATCC25175 & Pseudomomas aeruginosa & ATCC33467 \\
\hline Streptococcus oralis & ATCC35037 & Staphylococcus aureus & ATCC25923 \\
\hline Streptococcus sanguinis & ATCC10556 & Staphylococcus.aureus yellow strain & GUH070921 \\
\hline Tannerella forsythia & ATCC43037 & Staphylococcus aureus white strain & GUH070922 \\
\hline Treponema denticola & ATCC354405 & Staphylococcus epidermis & DSMZ20044 \\
\hline Treponema socranskii & D40DR2 & Staphylococcus haemolyticus & DSMZ20263 \\
\hline \multirow[t]{2}{*}{ Veillonella parvula } & ATCC 10790 & Streptococcus agalactiae & GUH230282 \\
\hline & & Varibaculum cambriense & GUH070917 \\
\hline
\end{tabular}

ATCC American type culture collection, $D$ sample from Forsyth Institute, Boston, MA, USA, GUH Ghent University Hospital Collection, Ghent, Belgium

\section{Results}

The mean age of the 19 women, who all delivered a child without complications, was 32 years (S.D. \pm 4 years, range
26-42). Clinical periodontal conditions during the pregnancies have been reported elsewhere [8]. Briefly, and at the 12 th week of pregnancy, $1.5 \%$ of sites (six sites per tooth examined) had a PPD $>4 \mathrm{~mm}$ which changed to $1.4 \%$ at the 
4-6 weeks postpartum examination. At week 12, the mean PPD was $2.4 \mathrm{~mm}$ (S.D. \pm 0.4 ). At 4-6 weeks postpartum, the mean PPD was $2.3 \mathrm{~mm}$ (S.D. \pm 0.3$)(p=0.34)$. Evidence of gingival hyperplasia was found at $8.7 \%$ of sites at the 12 th week of pregnancy and at $9.1 \%$ at $4-6$ weeks postpartum. On average, these women had 29 teeth (S.D. \pm 1.5 ). A clinical diagnosis of gingivitis was made in all of the 19 subjects. None of the subjects could be identified as having periodontitis. A decrease in BOP scores from a mean of $41.2 \%$ (S.D. $\pm 18.6 \%$ ) at week 12 of pregnancy to $26.6 \%$ (S. D. $\pm 14.4 \%)$ at the $4-6$ weeks postpartum examination was found $(p<0.001)$. The proportion of sites with BOP at week 12 was significantly correlated with the proportion of sites with BOP at $4-6$ weeks postpartum $(r=0.73, p<0.001)$ (Fig. 1).

Microbiological changes between week 12 of pregnancy to 4-6 weeks postpartum and in relation to changes in gingival inflammation (in percent, sites with BOP) between week 12 of pregnancy and 4-6 weeks postpartum

The distributions of selected bacteria are presented (Table 2). At week 12, as well as at the 4-6 weeks postpartum examinations, no differences in bacterial counts were found between women with a diagnosis of gingivitis or periodontitis, respectively. Thus, independent of the periodontal diagnosis, the following microorganisms were found at significantly higher counts at week 12 than at the microbiological sampling 4-6 weeks postpartum: Eubacterium saburreum, Parvimonas micra, Selenomonas noxia, and Staphylococcus aureus $(p<0.001)$. Mobiluncus curtisii presented with the

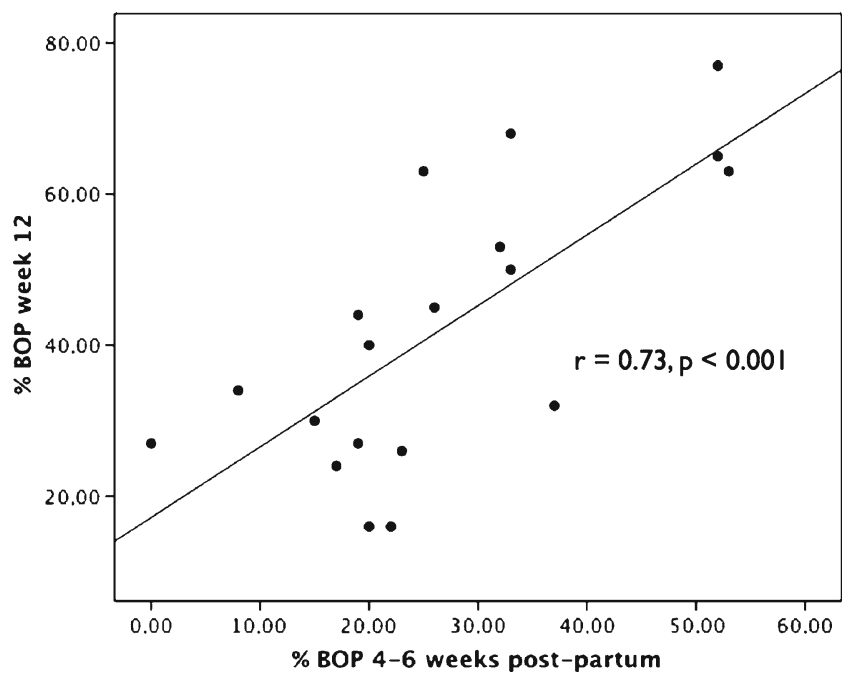

Fig. 1 Scatterplot diagram illustrating the relationship between percent BOP scores at week 12 of pregnancy and percent BOP scores at 4-6 weeks postpartum
Table 2 Frequency distribution (in percent) of selected bacteria at week 12 and at 4-6 weeks postpartum at $10^{4}$ and $10^{5}$ bacterial cell cutoff levels

\begin{tabular}{lrrrrr}
\hline & \multicolumn{2}{l}{ Week 12 } & & \multicolumn{2}{c}{ 4-6 weeks post-partum } \\
\cline { 2 - 3 } \cline { 6 - 6 } \cline { 6 - 6 } & $10^{4}$ cells & $10^{5}$ cells & & $10^{4}$ cells & $10^{5}$ cells \\
\hline E. saburreum & 100.0 & 5.3 & & 100.0 & 0.0 \\
M. curtisii & 5.3 & 0.0 & & 43.1 & 9.0 \\
P. micra & 100.0 & 5.3 & & 84.0 & 0.0 \\
S. noxia & 100.0 & 10.5 & & 73.7 & 5.3 \\
S. aureus & 100.0 & 36.8 & & 89.5 & 5.3 \\
\hline
\end{tabular}

opposite pattern. The changes for S. aureus and P. micra are presented in Fig. 2.

The subject-based proportions of BOP scores at week 12 of pregnancy were significantly correlated with the bacterial counts of Actinomyces israelii $(r=0.62, p=0.006)$, Actinomyces naeslundii $(r=0.56, p=0.012)$, Actinomyces odontolyticus $(r=0.61, p=0.006)$, Bifidobacterium bifidum $(r=0.61$, $p=0.006)$, Lactobacillus acidophilus $(r=0.60, p=0.006)$, Treponema socranskii $(r=0.61, p=0.006)$, and $P$. gingivalis $(r=0.56, p=0.012)$.

At 4-6 weeks postpartum, statistically significant correlations between the BOP scores and the bacterial counts were found for: Actinomyces neuii $(r=0.57, p<0.01)$, Atopobium parvulum $(r=0.61, p=0.006)$, Bifidobacterium biavatii $(r=0.61, p=0.006)$, B. bifidum $(r=0.71, p=0.001)$, Bifidobac terium breve $(r=0.71, p=0.001)$, Corynebacterium aurimuco$\operatorname{sum}(r=0.70, p=0.001)$, Corynebacterium nigricans $(r=0.63$, $p=0.001)$, Enterococcus faecalis $(r=0.63, p=0.003), M$.

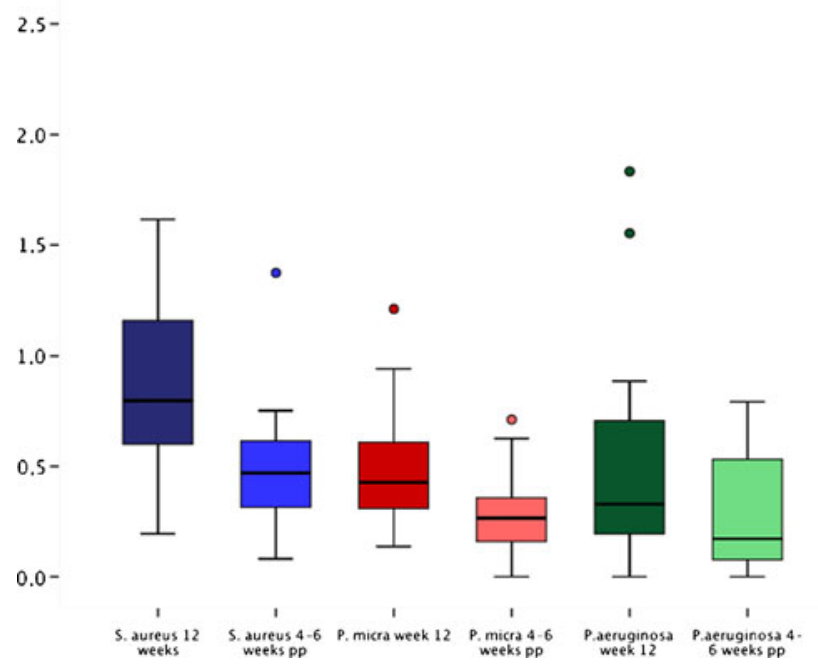

Fig. 2 Boxplot diagram illustrating the levels of $S$. aureus and $P$. micra at week 12 of pregnancy and 4-6 weeks postpartum. $X$-axis $=$ $1.0 \times 10^{5}$ bacterial cells; circles with different colors outlier values 
curtisii ( $r=0.68, p=0.001)$, Mobiluncus mulieris $(r=0.71$, $p=0.001)$, P. intermedia $(r=0.62, p=0.005)$, Pseudomonas aeruginosa $(r=0.002, p=0.001)$, Tannerella forsythia $(r=0.59, p=0.008)$, Streptococcus agalactiae $(r=0.58$, $p=0.007)$, Treponema denticola $(r=0.89, p=0.001)$, and $T$. socranskii $(r=0.61, p=0.006)$.

The significant correlations between changes in bacterial levels are presented (Table 3). The highest level of a correlation in bacterial counts between week 12 of pregnancy and 4-6 weeks postpartum was identified between changes of Porphyromonas endodontalis and P. aeruginosa $(r=0.99$, $p<0.001)$.

Association between levels of mRNA of proinflammatory cytokines in gingival fluid and the severity of gingival inflammation (in percent, sites with BOP) at week 12 of pregnancy and 4-6 weeks postpartum

Neither at the week 12, nor at the 4-6 weeks post-partum examinations were BOP scores correlated with cytokine values.

Differences in GCF cytokine levels of mRNA (IL-1 $\alpha$, IL-1 $\beta$, IL- 8 , TNF- $\alpha$, and SLPI) at the 12th week of pregnancy and 4-6 weeks postpartum

At week 12, as well as at the 4-6 weeks postpartum examination, no differences in the GCF mRNA cytokine levels studied were found between women with a diagnosis of gingivitis or periodontitis. Thus, with all cases, included statistical analysis failed to demonstrate differences in GCF levels of mRNA: IL- $1 \alpha$, IL- $1 \beta$, IL- 8, TNF- $\alpha$, and SLPI between samples from the 12th week of pregnancy and 4-6 weeks postpartum.

GCF levels of mRNA IL-8 were significantly correlated with mRNA IL-1 $\beta$ levels $(r=0.80, p<0.001)$. GCF levels of
mRNA IL-8 were also correlated with mRNA TNF- $\alpha$ levels $(r=0.63, p=0.003)$.

The GCF levels of mRNA SLPI at both the 12th week of pregnancy and at the 4-6 weeks postpartum assessments were significantly correlated with GCF levels of MRNA IL-1 $\alpha(r=0.49, p<0.001),(r=0.69, p=0.001)$, respectively. The reverse relationship between the changes in mRNA SLPI and mRNA Il- $1 \alpha$ between week 12 and 4-6 weeks postpartum $(r=-0.71, p<0.01)$ is presented in a scatterplot diagram (Fig. 3). GCF levels of mRNA IL-8 and mRNA IL$1 \beta$ were correlated with mRNA TNF- $\alpha$ levels $(r=0.66$, $p=0.002)$ and $(r=0.66, p<0.002)$ and correlated with the GCF levels of mRNA IL- $1 \alpha(r=-0.71, p<0.001)$, respectively. The changes in the levels of mRNA IL-8 and mRNA IL-1 $\beta$ between week 12 of pregnancy and the 4-6 week postpartum assessments were also significantly correlated $(r=-0.88, p<0.001)$. Statistical analysis failed to demonstrate correlations between changes in levels of the other cytokine combinations. Data on the mRNA TNF- $\alpha$ levels, mRNA Il-8, mRNA Il-1 $\beta$, and SLPI at week 12 and 4-6 weeks postpartum are presented in a boxplot diagram (Fig. 4).

The association between changes in bacterial and cytokine levels between week 12 of pregnancy and 4-6 weeks postpartum

Statistically significant correlations between changes in bacterial counts at 12 weeks of pregnancy and postpartum are presented (Table 4). Decreasing levels of $P$. endodontalis and $P$. aeruginosa were correlated with decreasing levels of mRNA Il-8 and mRNA Il-1 $\beta$. Decreasing levels of Bacteroides ureolyticus were correlated with decreasing expression of mRNA Il- $1 \alpha(r=0.48, p<0.05)$. It was noticeable that no correlations in changes in cytokine expression and bacterial changes were found for bacteria associated with periodontitis (P. gingivalis, T. forsythia, and T. denticola).

Table 3 Significant correlations between changes in subgingival counts of bacteria between week 12 of pregnancy and 4-6 weeks postpartum

A. neuii A. parvula B. biavatii E. faecalis M. curtisii P. aeruginosa P. micra P. endodontalis S. aureus S. agalactiae

\begin{tabular}{|c|c|c|c|c|c|c|c|c|c|c|}
\hline A. neuii & & & & & $0.61 * * *$ & $0.62 * * *$ & & $0.63 * * *$ & & \\
\hline A. parvula & & & $0.85^{* * *}$ & $0.83 * * *$ & $0.52 *$ & & & & & $0.81 * * *$ \\
\hline B. biavatii & & $0.95 * * *$ & & & $0.56^{* *}$ & & & & & $0.87 * * *$ \\
\hline E. faecalis & & $0.83 * * *$ & & & $0.46^{*}$ & & & & & $0.85 * * *$ \\
\hline M. curtisii & $0.61 * * *$ & $0.52 *$ & $0.56^{* *}$ & $0.46^{*}$ & & $0.73 * * *$ & & $0.71 * * *$ & & \\
\hline P. aeruginosa & $0.62 * * *$ & & & & $0.73 * * *$ & & & $0.99 * * *$ & & $0.64 * * *$ \\
\hline P. micra & & & & & & & & & $0.67 * * *$ & \\
\hline P. endodontalis & $0.63^{* * *}$ & & & & $0.71 * * *$ & $0.99 * * *$ & & & & $0.60^{* *}$ \\
\hline S. aureus & & & & & & & $0.67 * * *$ & & & \\
\hline S. agalactiae & & $0.81 * * *$ & $0.87 * * *$ & $0.85 * * *$ & & $0.64 * * *$ & & $0.60 * *$ & & \\
\hline
\end{tabular}

${ }^{*} p<0.05 ; * * p<0.01 ; * * * p<0.001$ 


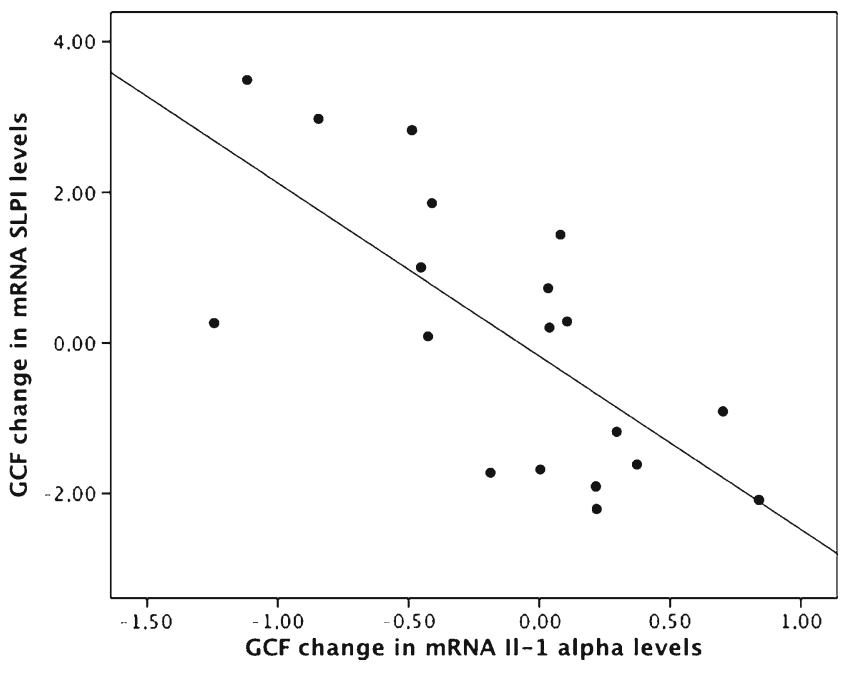

Fig. 3 Scatterplot diagram illustrating the relationship between changes in mRNA SLPI and mRNA IL- $1 \alpha$ between week 12 of pregnancy and the 4-6 weeks postpartum analysis

Explanatory variables to cytokine levels at week 12 and 4-6 weeks postpartum

GCF levels of mRNA IL-8 and mRNA IL-1 $\beta$ were explained by bacterial counts of $P$. endodontalis $(t=3.4, p<0.05),(t=4.6$, $p<0.001$ ), respectively. GCF levels of mRNA IL- $1 \alpha$ were explained by bacterial counts of B. ureolyticus $(t=5.7$, $p<0.001)$. High GCF levels of mRNA SLPI were associated with low counts of $P$. aeruginosa $(t=-3.1, p<0.001)$. GCF

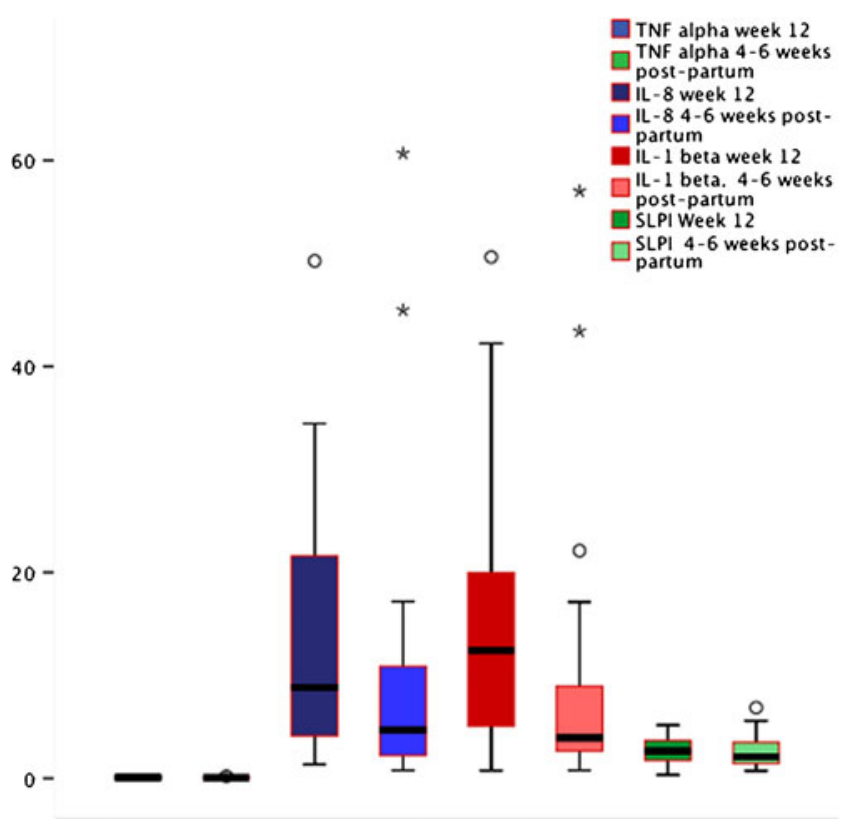

Fig. 4 Boxplot diagram illustrating mRNA cytokine levels at week 12 and at 4-6 weeks postpartum (empty circles represent outlier values and asterisks represents extreme outliers. Whiskers represent 25 th and 75 th percentiles)
Table 4 Statistically significant correlation coefficients between changes in cytokine and bacterial counts

\begin{tabular}{lllll}
\hline & IL-1 $\alpha$ & IL-1 $\beta$ & IL-8 & TNF- $\alpha$ \\
\hline B. ureolyticus & $-0.48^{*}$ & & & \\
C. aurimucosum & & & & $0.47^{*}$ \\
M. curtisii & & $-0.51^{*}$ & $-0.57^{* *}$ & \\
M. mulieris & & $-0.61^{* * *}$ & $-0.69^{* * *}$ & \\
P. aeruginosa & & $-0.47^{* *}$ & $-0.54^{*}$ & \\
P. endodontalis & & $-0.52^{*}$ & $-0.58^{*}$ & \\
S. agalactiae & & & $-0.50^{*}$ & \\
\hline
\end{tabular}

${ }^{*} p<0.05 ; * * p<0.01 ; * * * p<0.001$ (Pearson's correlation)

levels of mRNA TNF- $\alpha$ could not be explained by any of the counts of microorganisms studied.

\section{Discussion}

In the present study, pregnant women with a normal pregnancy outcome consecutively admitted to an obstetrics and gynecology ward were examined. The subject sample size in the present study was small but comparable to several other studies that have assessed specific factors in relation to pregnancy and periodontal conditions. One of the difficulties in assessing periodontal status during pregnancy can be the absence of radiographic evidence of bone loss or the interpretation of bone levels. Another problem may be the rather common finding of gingival hyperplasia that was found in $9 \%$ of the subjects in the present study. When we applied the same criteria as those used by Novak et al. 2008 [22] to the subjects in the present study all the pregnant women were diagnosed as only having gingivitis at both the 12th week and at the postpartum examination. The alveolar bone levels as assessed from available radiographs were within normal limits as was expected in this age cohort and clinical presentation.

Others have reported that approximately $40 \%$ to $50 \%$ of pregnant women have gingivitis [23]. In the present study population, the mean extent of BOP was $41.2 \%$ at 12 weeks of pregnancy. Although all subjects with no influence by the investigators had abstained from professional dental care during the pregnancy, the BOP scores decreased to, on average, $26.6 \%$ at $4-6$ weeks postpartum. The decrease in the extent of gingival inflammation could be the result of a physiological change, which may be explained by hormonal changes during pregnancy $[2,24]$. This would then also suggest that the hormonal changes may have an impact on mRNA cytokine expression in gingival tissues and fluids, while maintaining a balanced bacterial biofilm. In a recent study, data suggested that in premenopausal women only GCF levels of mRNA IL-6 levels peaked at the time of 
ovulation. This was not accompanied by clinical changes in the extent of gingival inflammation [25]. These authors failed to show changes in GCF levels of other proinflammatory cytokines during a normal menstrual cycle. Thus the impact of hormonal changes on gingival inflammation is unclear. In the present study, the change in mean PPD between week 12 and 4-6 weeks postpartum was statistically not significant and also clinically irrelevant. This may, in part explain the results obtained in regards to GCF changes in cytokines and bacterial counts.

The scientific evidence in regard to the subgingival microbiota during pregnancy in regard to bacterial counts is inconsistent $[2,4-7]$. This may, in part, be the result of differences in sampling methods and analysis, diagnostic criteria, treatment provided or not, age of the pregnant subjects, general health status, and, i.e., smoking habits. The observations in the present study suggested that the microbiota assessed overall was stable between the 12th week of pregnancy and until 4-6 weeks postpartum some species would suggest that hormonal changes may not result in microbiological shifts.

The present study also identified that the extent of BOP both at week 12 of pregnancy and at 4-6 weeks postpartum was associated with a complex microbiota dominated by bacteria associated with gingivitis. Significantly higher counts of E. saburreum, P. micra, S. noxia, and $S$. aureus were, however, found at week 12 of pregnancy than at the 4-6 week postpartum examination, suggesting a decrease for these species. In contrast $M$. curtisii increased from week 12 of pregnancy to 4-6 week postpartum. E. saburreum, M. curtisii, and S. noxia are commensal oral bacteria, while $P$. micra is a grampositive, anaerobic bacterium and has been associated with periodontal destruction [26]. S. aureus infection has been associated with periodontitis [27] but is also found in periodontally healthy subjects. It is noticeable that the counts of bacteria commonly associated with periodontitis did not change during the study period. The overall stable oral microbiota noticed in the present study is consistent with the perception of a stable vaginal microbiota during normal pregnancies and in the absence of bacterial vaginosis.

The inclusion of a study method to assess mRNA cytokine levels in GCF was made based on a common principle to assess various enzymes in GCF and primarily expressed by immune competent cells, i.e., polymorphonuclear cells (PMN cells). PMN cells constitute a major component of the cellular component in GCF.

No differences in mRNA detected in GCF for IL- $1 \alpha$, IL$1 \beta$, IL-8, TNF- $\alpha$, and SLPI between week 12 and postpartum were found. Thus, the changes in gingival inflammation (BOP) may only weakly be associated with the expression of these selected cytokines in GCF during pregnancy.

In the present study, consistent correlations between the levels of mRNA: IL- $1 \beta$, TNF- $\alpha$, and IL-8 during pregnancy and postpartum were identified. IL- $1 \beta$ and TNF- $\alpha$ are potent proinflammatory cytokines. IL- $1 \beta$ induces chemotaxis of leukocytes by inducing the production of IL-8 [28]. During pregnancy, there is a decrease in B cell response due to progressive increase of progesterone and estrogens, which reaches the peak in the third trimester [29]. P. endodontalis LPS is capable of stimulating PMNs to produce chemotactic cytokines [30]. In the present study, an upregulation of IL-8 and IL- $1 \beta$ was associated with higher levels of $P$. endodontalis.

Information about the relationship between bacteria in periodontal pockets/sulci and presence or absence of proinflammatory cytokines is limited. This may partly be explained by difficulties to accurately assess levels of proinflammatory cytokines in GCF. The use of a high-capacity cDNA reverse transcription method using housekeeping genes as standard references and to use gene expression to quantify cytokines $[31,32]$ in relation periodontal inflammation and bacterial presence during pregnancy might overcome this problem.

SLPI is a neutrophil elastase inhibitor with antibacterial and with anti-inflammatory properties [33]. While SLPI is associated with antibacterial and anti-inflammatory conditions, IL- $1 \alpha$ suggests an early phase of inflammation. In the present study a significant correlation was found between the changes in GCF levels of SLPI and IL- $1 \alpha$ both at week 12 of pregnancy and postpartum. The period between the 12 th week of pregnancy and the postpartum examination may therefore reflect a transient phase of inflammation in pregnant/post-delivery women.

In the present study, the levels of the SLPI cytokine were inversely correlated with counts of $P$. aeruginosa but only postpartum. $P$. aeruginosa is a known pathogen in chronic infections and identified in periodontitis [34] High counts of SLPI are consistent with low counts of pathogens, which is consistent with periodontal conditions postpartum in the women participating in the present study.

In gingival inflammation, GCF is secreted by and through the sulcular epithelium and this exudate is rich in cellular elements specifically leucocytes, primarily neutrophils, and lymphocytes. Bacterial stimuli induce production of proinflammatory cytokines facilitating the host immune system to control the infectious agents. Data suggest that the levels of cytokines in GCF are associated with periodontal disease status [35]. However bacteria, i.e., P. gingivalis can modulate important host signaling cytokine responses [36]. In the present study, we assessed mRNA expression of proinflammatory cytokines and the SLIPI while accounting for bacterial presence in GCF. The lack of agreement between bacterial levels in GCF and the assessments of cytokine messenger mRNA identified in the present study may reflect the imbalance in the abilities between host and infectious agents which was also reflected by gingival status 
in pregnant women. It might be that the primary line of host defense is not in GCF but in gingival tissues and where the mRNA expression of cytokines through competent immune cells prevent bacteria invasion.

To conclude, BOP decreased between the week 12 of pregnancy and postpartum. Therefore, moderate gingivitis during pregnancy may partially resolve without any active therapy. GCF levels of proinflammatory cytokines were correlated with each other. Specifically decreasing expression of proinflammatory cytokines and levels of some bacteria (i.e., B. ureloyticus, $P$. aeruginosa, and $P$. endodontalis) appears to be explanatory to clinical periodontal improvements 46 weeks postpartum. However, we were unable to explain the difference in susceptibility to pregnancy gingivitis with elevated proinflammatory cytokine levels during pregnancy. In the future, studies with larger populations are needed in this field of research.

Acknowledgments We highly appreciate the laboratory support by Ms. Marianne Weibel and Ms. Regula Hirschi for microbiological processing, and by Ms. Catherine Solioz-Fehlmann for working with real-time PCR and cytokine analysis.

Conflict of interest and source of funding statement The authors declare that they have no conflict of interest. The University of Bern, Switzerland, and the Clinical Research Foundation for the Promotion of Oral Health, Brienz, Switzerland funded the study.

\section{References}

1. Loe H, Silness J (1963) Periodontal disease in pregnancy. I. Prevalence and severity. Acta Odontol Scand 21:533-551

2. Kornman KS, Loesche WJ (1980) The subgingival microbial flora during pregnancy. J Periodontal Res 15:111-122

3. Tilakaratne A, Soory M, Ranasinghe AW, Corea SM, Ekanayake SL, de Silva M (2000) Periodontal disease status during pregnancy and 3 months post-partum, in a rural population of Sri-Lankan women. J Clin Periodontol 27:787-792

4. Gursoy M, Pajukanta R, Sorsa T, Kononen E (2008) Clinical changes in periodontium during pregnancy and post-partum. J Clin Periodontol 35:576-583

5. Jensen J, Liljemark W, Bloomquist C (1981) The effect of female sex hormones on subgingival plaque. J Periodontol 52:599-602

6. Carrillo-de-Albornoz A, Figuero E, Herrera D, Bascones-Martinez A (2010) Gingival changes during pregnancy: II. Influence of hormonal variations on the subgingival biofilm. J Clin Periodontol 37:230-240

7. Jonsson R, Howland BE, Bowden GH (1988) Relationships between periodontal health, salivary steroids, and Bacteroides intermedius in males, pregnant and non-pregnant women. J Dent Res 67:1062-1069

8. Adriaens LM, Alessandri R, Sporri S, Lang NP, Persson GR (2009) Does pregnancy have an impact on the subgingival microbiota? $\mathrm{J}$ Periodontol 80:72-81

9. Ramseier CA, Kinney JS, Herr AE, Braun T, Sugai JV, Shelburne CA, Rayburn LA, Tran HM, Singh AK, Giannobile WV (2009) Identification of pathogen and host-response markers correlated with periodontal disease. J Periodontol 80:436-446
10. Teles RP, Likhari V, Socransky SS, Haffajee AD (2009) Salivary cytokine levels in subjects with chronic periodontitis and in periodontally healthy individuals: a cross-sectional study. J Periodontal Res 44:411-417

11. Bastos MF, Lima JA, Vieira PM, Mestnik MJ, Faveri M, Duarte PM (2009) TNF-alpha and IL-4 levels in generalized aggressive periodontitis subjects. Oral Dis 15:82-87

12. Markou E, Boura E, Tsalikis L, Deligianidis A, Konstantinidis A (2011) The influence of sex hormones on proinflammatory cytokines in gingiva of periodontally healthy premenopausal women. $\mathrm{J}$ Periodontal Res. doi:10.1111/j.1600-0765.2011.01369.x

13. Figuero E, Carrillo-de-Albornoz A, Herrera D, Bascones-Martinez A (2010) Gingival changes during pregnancy: I. Influence of hormonal variations on clinical and immunological parameters. J Clin Periodontol 37:220-229

14. Into $T$, Inomata $M$, Kanno $Y$, Matsuyama $T$, Machigashira $M$, Izumi Y, Imamura T, Nakashima $\mathrm{M}$, Noguchi T, Matsushita $\mathrm{K}$ (2006) Arginine-specific gingipains from Porphyromonas gingivalis deprive protective functions of secretory leucocyte protease inhibitor in periodontal tissue. Clin Exp Immunol 145:545-554

15. Weldon S, McGarry N, Taggart CC, McElvaney NG (2007) The role of secretory leucoprotease inhibitor in the resolution of inflammatory responses. Biochem Soc Trans 35(Pt 2):273-276

16. Henriksen PA, Hitt M, Xing Z, Wang J, Haslett C, Riemersma RA, Webb DJ, Kotelevtsev YV, Sallenave JM (2004) Adenoviral gene delivery of elafin and secretory leukocyte protease inhibitor attenuates NF-kappa B-dependent inflammatory responses of human endothelial cells and macrophages to atherogenic stimuli. J Immunol 172:45354544

17. Nakamura-Minami M, Furuichi Y, Ishikawa K, Mitsuzono-Tofuku Y, Izumi Y (2003) Changes of alpha1-protease inhibitor and secretory leukocyte protease inhibitor levels in gingival crevicular fluid before and after non-surgical periodontal treatment. Oral Dis 9:249-254

18. Sano C, Shimizu T, Sato K, Kawauchi H, Tomioka H (2000) Effects of secretory leucocyte protease inhibitor on the production of the anti-inflammatory cytokines, IL-10 and transforming growth factor-beta (TGF-beta), by lipopolysaccharide-stimulated macrophages. Clin Exp Immunol 121:77-85

19. Socransky SS, Haffajee AD, Smith C, Martin L, Haffajee JA, Uzel NG, Goodson JM (2004) Use of checkerboard DNA-DNA hybridization to study complex microbial ecosystems. Oral Microbiol Immunol 19:352-362

20. Persson GR, Weibel M, Hirschi R, Katsoulis J (2008) Similarities in the subgingival microbiota assessed by a curet sampling method at sites with chronic periodontitis. J Periodontol 79:2290-2296

21. Smith GL, Socransky SS, Smith CM (1989) Rapid method for the purification of DNA from subgingival microorganisms. Oral Microbiol Immunol 4:47-51

22. Novak MJ, Novak KF, Hodges JS, Kirakodu S, Govindaswami M, Diangelis A, Buchanan W, Papapanou PN, Michalowicz BS (2008) Periodontal bacterial profiles in pregnant women: response to treatment and associations with birth outcomes in the obstetrics and periodontal therapy (OPT) study. J Periodontol 79:1870-1879

23. Dinas K, Achyropoulos V, Hatzipantelis E, Mavromatidis G, Zepiridis L, Theodoridis T, Dovas D, Tantanasis T, Goutzioulis F, Bontis J (2007) Pregnancy and oral health: utilisation of dental services during pregnancy in northern Greece. Acta Obstet Gynecol Scand 86:938-944

24. Straka M (2011) Pregnancy and periodontal tissues. Neuro Endocrinol Lett 32:34-38

25. Markou E, Boura E, Tsalikis L, Deligianidis A, Konstantinidis A (2011) The influence of sex hormones on proinflammatory cytokines in gingiva of periodontally healthy premenopausal women. J Periodontal Res 46:528-532. doi:10.1111/j.1600-0765.2011.01369.x

26. Gomes SC, Piccinin FB, Oppermann RV, Susin C, Nonnenmacher CI, Mutters R, Marcantonio RA (2006) Periodontal status in smokers and 
never-smokers: clinical findings and real-time polymerase chain reaction quantification of putative periodontal pathogens. J Periodontol $77: 1483-1490$

27. Fritschi BZ, Albert-Kiszely A, Persson GR (2008) Staphylococcus aureus and other bacteria in untreated periodontitis. J Dent Res 87:589-593

28. Cohen J (2002) The immunopathogenesis of sepsis. Nature 420:885-891

29. Raber-Durlacher JE, Leene W, Palmer-Bouva CC, Raber J, Abraham-Inpijn L (1993) Experimental gingivitis during pregnancy and post-partum: immunohistochemical aspects. J Periodontol 64:211-218

30. Ko HJ, Lim SS (2002) Production of macrophage inflammatory protein (MIP)-1alpha and MIP-1beta by human polymorphonuclear neutrophils stimulated with Porphyromonas endodontalis lipopolysaccharide. J Endod 28:754-757

31. Yin JL, Shackel NA, Zekry A, McGuinness PH, Richards C, Putten KV, McCaughan GW, Eris JM, Bishop GA (2001) Realtime reverse transcriptase-polymerase chain reaction (RT-PCR) for measurement of cytokine and growth factor mRNA expression with fluorogenic probes or SYBR Green I. Immunol Cell Biol 79:213-221

32. Overbergh L, Giulietti A, Valckx D, Decallonne R, Bouillon R, Mathieu C (2003) The use of real-time reverse transcriptase PCR for the quantification of cytokine gene expression. J Biomol Tech $14: 33-43$

33. King AE, Critchley HO, Kelly RW (2000) Presence of secretory leukocyte protease inhibitor in human endometrium and first trimester decidua suggests an antibacterial protective role. Mol Hum Reprod 6:191-196

34. da Silva-Boghossian CM, do Souto RM, Luiz RR, Colombo AP (2011) Association of red complex, A. actinomycetemcomitans and non-oral bacteria with periodontal diseases. Arch Oral Biol 56:899-906

35. Gamonal J, Acevedo A, Bascones A, Jorge O, Silva A (2000) Levels of interleukin-1 beta, -8 , and -10 and RANTES in gingival crevicular fluid and cell populations in adult periodontitis patients and the effect of periodontal treatment. J Periodontol 71:1535-1545

36. Moffatt CE, Lamont RJ (2011) Porphyromonas gingivalis induction of microRNA-203 expression. Infect Immun 201179:2632-2637 